Article

\title{
Comparison among Methods for Induction Motor Low-Intrusive Efficiency Evaluation Including a New AGT Approach with a Modified Stator Resistance
}

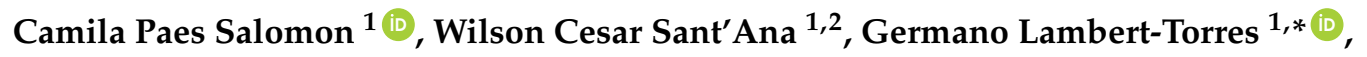 \\ Luiz Eduardo Borges da Silva ${ }^{2}$, Erik Leandro Bonaldi ${ }^{1}$ and Levy Ely de Lacerda de Oliveira ${ }^{1}$ \\ 1 Gnarus Institute, Itajuba 37500-052, Brazil; camila.gnarus@gmail.com (C.P.S.); \\ wilson.cesar.santana@gmail.com (W.C.S.); erik@pssolucoes.com.br (E.L.B.); \\ levy@pssolucoes.com.br (L.E.d.L.d.O.) \\ 2 Institute of System Engineering and Information Technology, Itajuba Federal University, \\ Itajuba 37500-903, Brazil; leborgess@gmail.com \\ * Correspondence: germanoltorres@gmail.com; Tel.: +55-35-99-986-0378
}

Received: 25 February 2018; Accepted: 15 March 2018; Published: 21 March 2018

check for updates

\begin{abstract}
Induction motors consume a great portion of the generated electrical energy. Moreover, most of them work at underloaded conditions, so they have low efficiencies and waste a lot of energy. Because of this, the efficiency estimation of in-service induction motors is a matter of great importance. This efficiency estimation is usually performed through indirect methods, which do not require invasive measurements of torque or speed. One of these methods is the modified Air-Gap Torque (AGT) method, which only requires voltage and current data, the stator resistance value, and the mechanical losses. This paper approaches the computation of a modified stator resistance including the mechanical losses effect to be applied in the AGT method for torque and efficiency estimation of induction motors. Some improvements are proposed in the computation of this resistance by using a direct method, as well as the possibility to estimate this parameter directly from the nameplate data of the induction motor. The proposed methodology only relies on line voltages, currents, and nameplate data and is not intrusive. The proposed methodology is analyzed through simulation and validated through experimental results with three-phase induction motors. Also, a comparison of methods for in-service induction motors efficiency estimation is presented for the tested motors.
\end{abstract}

Keywords: condition monitoring; efficiency estimation; air-gap torque; induction motors; stator resistance

\section{Introduction}

Induction motors (IMs) are widely used in industries because of their advantages and the recent advances in control techniques. In industries, about $70 \%$ to $80 \%$ of the consumed electrical energy is transformed in mechanical energy by the electrical motors. Thus, if an average efficiency of $80 \%$ is considered in this process, then about $15 \%$ of the total consumed electrical energy turns to losses in the motors. These energy losses directly affect financial losses and indirectly affect power system planning. Thus, the efficiency evaluation of in-service IMs has become an important issue as well as the condition monitoring of these machines [1-4].

The efficiency of an electrical motor is computed as the ratio of the shaft power to the electrical power [5]. The electrical power is the input power related to the electrical motor supply. This power can be easily calculated from the voltage and current data. In the process of converting electrical to mechanical power, there are different types of losses. Thus, the shaft power is the output power, which 
is the mechanical power available on the motor shaft. The shaft power depends on the shaft torque and the rotor speed measurements. However, a robust and reliable torque meter is expensive, and its installation may not be possible for some in-service machines. Besides, these devices can require appropriate calibration and maintenance $[2,6]$.

Therefore, indirect methods for induction motor efficiency estimation are preferred, as they do not require direct measurements of torque or speed and so they are non-invasive for the industrial process [7]. Nowadays, condition monitoring systems have becoming increasingly present in industries. Moreover, the energy consumption and rotor speed estimation functions require similar data to be implemented, which are normally available in the condition monitoring systems. Therefore, the current trend is to integrate these functions as features of these systems [4,8-11]. Because of the previously mentioned facts, several efficiency estimation methods for in-service induction motors have been proposed. For instance, there are methods based on induction motor slip [7,12], current [13], equivalent circuit $[14,15]$, and air-gap torque [1,16-19]. Some of these methods are approached in this work and are explained in the following paragraphs.

The slip method is recommended when there are available measurements of IM rotor speed. This method is based on a linearization on the torque/speed curve of the IM considering the synchronous speed, rated speed, and current operation speed. As the torque values associated to the rated speed and synchronous speed are known from the torque/speed curve, the current operation torque is obtained by a relation based on triangle similarity using the mentioned known torque and speed parameters. In [7], some improvements have been proposed for the slip method, including a correction on the rated speed value, which allows the method to provide a more accurate torque estimation.

The no-load current method is similar to the slip method but is based on current measurements instead of speed measurements. The method adopts a proportion between the output power and the operating current of the motor. The relation between the current and the rated shaft power is given by the following expression [13]:

$$
\frac{P_{\text {shaft }}}{P_{\text {rated }}}=\left(\frac{I_{m}-I_{0}}{I_{\text {rated }}-I_{0}}\right)
$$

where $P_{\text {rated }}$ is the rated shaft power; $P_{\text {shaft }}$ is the current operation shaft power, $I_{m}$ is the measured current; $I_{\text {rated }}$ is the rated current, and $I_{0}$ is the no-load current.

The Air-Gap Torque (AGT) method for induction motor efficiency estimation is based on the computation of the air-gap torque equations and requires the following data to be measured: line voltages, line currents, stator resistance, and mechanical losses [16]. The main advantages of this method over the others are its accuracy and ease of implementation [17]. Regarding the required data, the line voltages and line currents are easily collected from the condition monitoring system. However, as regards disadvantages, the stator resistance and the mechanical losses are parameters generally obtained through experimental tests, and they are significant to the performance of this method [18].

In a previous paper [1], a new concept of stator resistance including the mechanical losses effect to be used in the AGT method has been proposed. This resistance was estimated by using a Particle Swarm Optimization (PSO)-based algorithm aiming to minimize the torque error at the rated operation point. The proposed methodology reached good results for torque and efficiency estimation in comparison with other conventional methods. The present work proposes a new methodology for computing this modified stator resistance by using a direct method instead of a PSO algorithm, which allows the estimation to be simpler and more robust than that proposed in [1]. Also, it proposed a variant method for estimating this resistance when the monitored IM does not operate close to the rated operation point. The motivation is that the IMs under monitoring may not operate close enough to the rated point during the lifetime, and this was a requirement for the methodology presented in [1]. Thus, with this new proposal, it is not necessary to operate close to the rated operation point to estimate the modified stator resistance. The methodology proposed in the current paper is validated through simulation and preliminary experimental tests performed for a $0.5-\mathrm{HP}$ two-pole three-phase induction 
motor. Moreover, a comparison among low-intrusive efficiency estimation methods is presented for the tested motors. The main advantages of the proposed methodology are the ease of implementation and its low intrusiveness, as it only relies on line currents, line voltages, and nameplate data.

\section{Methods for Induction Motor Efficiency Estimation}

This section presents a review of the methods for IM efficiency estimation approached in the paper. Focus is given for the AGT method since the proposed methodology is based on it.

\subsection{Air-Gap Torque Method}

The AGT method relies on the computation of the air-gap torque by considering the stator flux equations, obtained by integrating the stator voltages. The voltage equations of a three-phase IM are given by $[20,21]$ :

$$
\begin{aligned}
& v_{a}=\frac{d \psi_{a}}{d t}+R_{s} i_{a} \\
& v_{b}=\frac{d \psi_{b}}{d t}+R_{s} i_{b} \\
& v_{c}=\frac{d \psi_{c}}{d t}+R_{s} i_{c}
\end{aligned}
$$

where $v_{a}, v_{b}$, and $v_{c}$ are the phase voltages; $i_{a}, i_{b}$, and $i_{c}$ are the phase currents; $\psi_{a}, \psi_{b}$, and $\psi_{c}$ are the flux linkages of windings $a, b$, and $c$, respectively; and $R_{s}$ is the phase stator resistance.

Considering the instantaneous phase voltages and phase currents, the instantaneous input power, $p_{\text {input }}$, of a three-phase IM is given by:

$$
p_{\text {input }}=v_{a} i_{a}+v_{b} i_{b}+v_{c} i_{c}
$$

Thus, by substituting (2) in (3),

$$
p_{\text {input }}=i_{a}\left(\frac{d \psi_{a}}{d t}+R_{s} i_{a}\right)+i_{b}\left(\frac{d \psi_{b}}{d t}+R_{s} i_{b}\right)+i_{c}\left(\frac{d \psi_{c}}{d t}+R_{s} i_{c}\right)
$$

From (2), the flux linkages can be given as:

$$
\begin{aligned}
& \psi_{a}=\int\left(v_{a}-R_{s} i_{a}\right) d t \\
& \psi_{b}=\int\left(v_{b}-R_{s} i_{b}\right) d t \\
& \psi_{c}=\int\left(v_{c}-R_{s} i_{c}\right) d t
\end{aligned}
$$

The general equation of the air-gap torque, $T_{e}$, is given by [22]:

$$
T_{e}=\frac{N P}{2 \sqrt{3}}\left[i_{a}\left(\psi_{c}-\psi_{b}\right)+i_{b}\left(\psi_{a}-\psi_{c}\right)+i_{c}\left(\psi_{b}-\psi_{a}\right)\right]
$$

where $N P$ is the number of poles.

By performing some mathematical manipulations and considering the line data, which are more usual to be measured in practice, the air-gap torque is given by:

$$
T_{e}=\frac{N P}{2 \sqrt{3}}\left\{\left(i_{A}-i_{B}\right) \cdot \int\left[v_{C A}-R_{S}\left(i_{C}-i_{A}\right)\right] d t-\left(i_{C}-i_{A}\right) \cdot \int\left[v_{A B}-R_{S}\left(i_{A}-i_{B}\right)\right] d t\right\}
$$

where the upper-case suffix in the electrical quantities denotes the line data.

In the case of a $Y$-connected motor without a neutral connection or a delta-connected motor, $i_{B}=-\left(i_{A}+i_{C}\right)$. Thus, Equation (7) can be rewritten to use only two-line voltages and two-line currents, reducing the number of required input data to calculate the air-gap torque.

$$
T_{e}=\frac{N P \cdot}{2 \sqrt{3}}\left\{\left(2 \cdot i_{A}+i_{C}\right) \cdot \int\left[v_{C A}-R_{S}\left(i_{C}-i_{A}\right)\right] d t-\left(i_{C}-i_{A}\right) \cdot \int\left[v_{A B}-R_{S}\left(2 \cdot i_{A}+i_{C}\right)\right] d t\right\}
$$


After the computation of the air-gap torque, the motor efficiency is calculated by [8]:

$$
\eta=\frac{T_{\text {shaft }} \cdot \omega_{r}}{P_{\text {input }}}=\frac{T_{e} \cdot \omega_{r}-W_{f w}-W_{L L r}}{P_{\text {input }}}
$$

where $T_{\text {shaft }}$ is the IM shaft torque, $\omega_{r}$ is the rotor rotation speed, $P_{\text {input }}$ is the electrical real power (input power), $W_{f w}$ is the friction and windage loss, and $W_{L L r}$ is the rotor stray load loss. The input of active power is obtained by computing the average of the input power $p_{\text {input }}$ given by (2).

The conventional AGT method for evaluating efficiency requires the mechanical losses value, which should be obtained from experimental tests. Nevertheless, the execution of experimental tests can be complicated or impracticable for in-service motors. The modified stator resistance approached in this current paper already includes the mechanical losses effect. Thus, these losses do not need to be considered apart from the AGT method.

\subsection{Slip Method}

The slip method is based on a linearization in the torque/speed curve, considering the points of IM synchronous speed, rated speed, and current operation speed. Figure 1 illustrates the mentioned linearization.

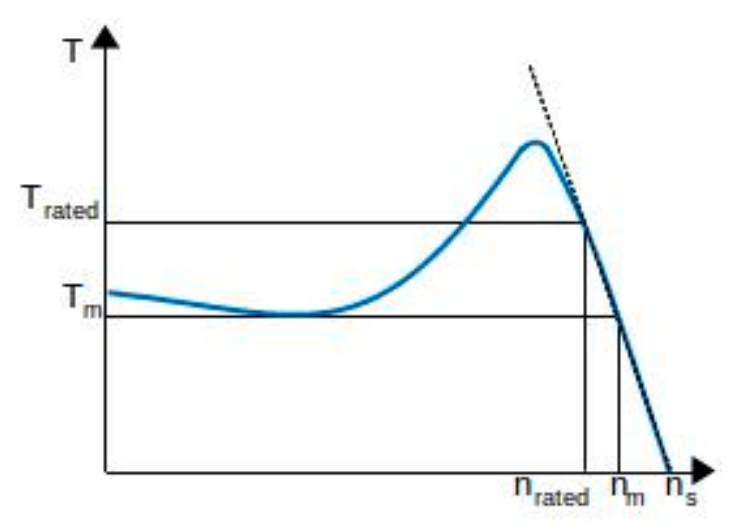

Figure 1. Torque versus speed curve linearization.

Thus, the operation torque can be estimated by $[7,8]$ :

$$
T_{m}=T_{\text {rated }} \cdot\left(\frac{n_{s}-n_{m}}{n_{s}-n_{\text {rated }}}\right)
$$

where $T_{m}$ is the current operation torque, $n_{S}$ is the synchronous speed, $n_{m}$ is the current operation speed, and $n_{\text {rated }}$ is the rated speed. An observation is that, in this paper, $n$ is the IM rotor rotation speed in (rpm) and $\omega$ is the rotor speed in (rad/s). Both will be referred as "rotor speed."

The torque can also be computed directly by using the slip.

$$
T_{m}=T_{\text {rated }} \cdot \frac{s_{m}}{s_{\text {rated }}}
$$

where $s_{m}$ is the current operation slip and $s_{\text {rated }}$ is the rated slip.

Finally, the IM efficiency can be computed by:

$$
\eta=\frac{T_{m} \cdot \omega_{m}}{P_{\text {input }}}
$$

where $\omega_{m}$ is the current operation rotor speed. 
This method may have poor accuracy because the standards NEMA MG1 and IEC 34-2-1 allow a deviation of maximum $20 \%$ in the nameplate rated speed about the true value. This could lead to a significant error on the estimation technique [7]. Thus, in [7], a correction for the rated speedhas been proposed, which is given by:

$$
n_{\text {rated }}^{*}=n_{\text {syn } 60}-\left(\frac{2 \cdot \pi \cdot T_{\text {rated }}}{60}\right) \cdot\left(\frac{n_{2} \cdot\left(n_{\text {syn } 2}-n_{2}\right)-n_{1} \cdot\left(n_{\text {syn } 1}-n_{1}\right)}{\Delta P \times \eta_{\text {rated }}}\right)
$$

where $n_{\text {rated }}^{*}$ is the corrected rated speed; $n_{s y n 60}, n_{s y n 1}$, and $n_{s y n 2}$ are synchronous speeds at rated frequency and at two different operation points, respectively (in this last case, it is considered the possibility of the IM fed by a frequency inverter); $T_{\text {rated }}$ is the rated torque; $n_{1}$ and $n_{2}$ are rotation speeds at two different operation points; $\Delta P$ is the electrical power variation between the two operation points; and $\eta_{\text {rated }}$ is the rated efficiency.

Thus, it is possible to obtain a corrected rated slip, by using the corrected rated speed instead of the rated speed. Thus, the output torque estimated in this modified slip method is given by:

$$
T_{m}=T_{\text {rated }} \cdot \frac{s_{m}}{s_{\text {rated }}^{*}}
$$

where $s^{*}$ rated is the corrected rated slip.

\subsection{No Load Current Method}

The no-load current method is based on current measurements and the no-load current information. In this method, the shaft power is computed by:

$$
P_{\text {shaft }}=P_{\text {rated }} \cdot\left(\frac{I_{m}-I_{0}}{I_{\text {rated }}-I_{0}}\right)
$$

where $P_{\text {rated }}$ is the rated shaft power, $P_{\text {shaft }}$ is the current operation shaft power, $I_{m}$ is the measured current, $I_{\text {rated }}$ is the rated current, and $I_{0}$ is the no-load current.

Thus, the shaft torque $\left(T_{m}\right)$ can be obtained by:

$$
T_{m}=\frac{P_{\text {shaft }}}{\omega_{m}}
$$

The efficiency can be obtained by using (12).

\section{Proposed Methodology for the Modified Stator Resistance Estimation}

The methodology proposed in this paper for the modified stator resistance estimation is an improvement of the method proposed in [1], considering a direct method to compute the resistance instead of a PSO based algorithm. The principle consists in estimating a stator resistance when the motor operates close to the rated operation point, minimizing the error of the calculated air-gap torque with relation to the rated (shaft) torque. Thus, as the unique estimated parameter is the stator resistance, this is a mathematical artifice that includes the physical stator resistance and an additional value equivalent to the mechanical losses effect. Although it is estimated close to the rated operation point, it can be used for the other operating conditions of the IM as well. Thus, the resulting torque calculated by using the AGT equations with this stator resistance is a good estimate for the shaft torque.

\subsection{Modified Stator Resistance Estimation—“Method 1"}

The modified stator resistance is estimated online when the motor operates close enough to the rated operation point, defined as $O P\left(n_{\text {rated }}, T_{\text {rated }}\right)$. The principle of the proposed method is to 
"force" the rated and the estimated air-gap torque to be equal to each other, which means that the error between them is equal zero. The torque error is given by (17):

$$
\text { error }=\left|T_{\text {rated }}-T_{e}\right|
$$

Thus, if error $=0$, it is obtained that:

$$
T_{e}=T_{\text {rated }}
$$

Let us consider the air-gap torque expression (7) only for estimating the modified stator resistance. By substituting (7) in (18), it comes to:

$$
\frac{N P}{2 \sqrt{3}}\left\{\left(i_{A}-i_{B}\right) \cdot \int\left[v_{C A}-R_{S}^{*}\left(i_{C}-i_{A}\right)\right] d t-\left(i_{C}-i_{A}\right) \cdot \int\left[v_{A B}-R_{S}^{*}\left(i_{A}-i_{B}\right)\right] d t\right\}=T_{\text {rated }}
$$

where $R_{S}{ }^{*}$ is the modified stator resistance to be estimated.

By isolating the stator resistance in (19), it comes to:

$$
\left[\left(i_{A}-i_{B}\right) \int\left(i_{C}-i_{A}\right) d t-\left(i_{C}-i_{A}\right) \int\left(i_{A}-i_{B}\right) d t\right] R_{s}^{*}=\left(i_{A}-i_{B}\right) \int v_{C A} d t-\left(i_{C}-i_{A}\right) \int v_{A B} d t-\frac{2 \sqrt{3}}{N P} T_{\text {rated }}
$$

Thus, consider that:

$$
\begin{gathered}
K_{A}=\left(i_{A}-i_{B}\right) \int\left(i_{C}-i_{A}\right) d t-\left(i_{C}-i_{A}\right) \int\left(i_{A}-i_{B}\right) d t \\
K_{B}=\left(i_{A}-i_{B}\right) \int v_{C A} d t-\left(i_{C}-i_{A}\right) \int v_{A B} d t-\frac{2 \sqrt{3}}{N P} T_{\text {rated }}
\end{gathered}
$$

The modified stator resistance is given by:

$$
R_{s}^{*}=\frac{K_{B}}{K_{A}}
$$

As the only parameter being estimated is the stator resistance and it is estimated by forcing the air-gap torque to be equal the shaft torque, it includes the mechanical losses effect (as these losses are the only "difference" between the air-gap torque and the shaft torque). Because of this characteristic, this resistance is to be used in the air-gap torque equation to provide an estimation for the shaft torque. Thus, in a given application, firstly the modified stator resistance is estimated by using (21) and (22), and only after that, the shaft torque is estimated by using (7) with the modified stator resistance.

In terms of practical implementation, the voltages and currents are periodically acquired, and the integrals are computed for each data sample. The dc components in the current and voltage data must be ignored to perform the integrals. They can be calculated numerically by using the trapezoidal method or other methods using Simpson's rule or Gauss's rule [20]. Thus, the terms $K_{A}$ and $K_{B}$ are simple numbers, allowing the calculation given by (22). The term $K_{A}$ must be different from zero. Finally, it is recommended to compute $R_{s}{ }^{*}$ by (22) by using the averages of the terms $K_{A}$ and $K_{B}$.

The proposed direct method algorithm, shown in Figure 2, can be compared with another published algorithm, proposed in [1], which is a modified stator resistance computing by using PSO algorithm. In both cases, the procedure is executed for each signals sample in the computational environment, and only when the rotor speed is close to the rated speed. The PSO algorithm is an iterative procedure, consists of some steps, and includes random values; whereas the direct method consists only of few sequential steps, is a deterministic method, and then is faster than the iterative procedure. 


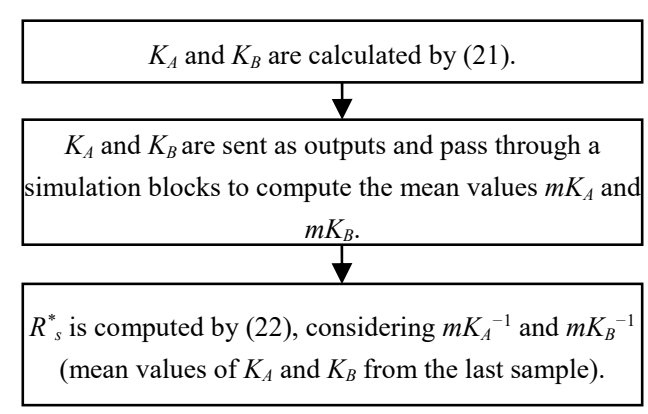

Figure 2. Modified stator resistance estimation-proposed direct method.

As a remark, it is important to note that the IM efficiency is also affected by the rotor resistance. However, this effect would be directly approached in the "equivalent circuit method" for IM efficiency estimation, which was not in the scope of this paper. The proposed methodology is based on the AGT method, and its mathematical model depends on the stator resistance but not on the rotor resistance. Moreover, the mathematical equations of the other approached methods (slip method, modified slip method, and no load current method) are not dependent on the rotor resistance. Therefore, the focus is on the stator resistance estimation and not on the rotor resistance.

Finally, it is important to emphasize that the "physical" stator resistance is dependent on the thermal effect. However, the proposed modified stator resistance is not simply the physical stator resistance; it is a mathematical artifice or a "fictitious" stator resistance that comprises the mechanical losses effect. As it is only a mathematical artifice, the thermal effect is not considered. This, indeed, can be considered as an advantage of the proposed method.

\subsection{Modified Stator Resistance Alternative Estimation Method from the IM Nameplate Data— "Method 2"}

A requirement for estimating the modified stator resistance including the mechanical losses effect is that the motor must operate at any moment close to the rated operation point. However, not all IMs will operate in this condition during their lifetime. Thus, this paper proposes an alternative way to estimate the modified stator resistance when the IM does not operate close to the rated operation point.

This alternative method consists in estimating the modified stator resistance directly from the nameplate data of the IM. The required nameplate data to perform this process are the rated voltage $V_{\text {rated }}$, rated current $I_{\text {rated }}$, rated supply frequency $f_{\text {rated }}$, and rated power factor $P F_{\text {rated }}$. First, fictitious signals of voltage and current at the rated operation point are generated from the nameplate data. The signals are considered to be balanced and symmetrical, and the phase shift between the fictitious rated current and voltage signals are computed from the rated power factor. The fictitious rated voltages are given by

$$
\begin{gathered}
v_{A B \_ \text {rated }}=\sqrt{2} V_{\text {rated }} \sin (\omega t) \\
v_{B C \_ \text {rated }}=\sqrt{2} V_{\text {rated }} \sin (\omega t-2 \pi / 3) \\
v_{C A \_ \text {rated }}=\sqrt{2} V_{\text {rated }} \sin (\omega t+2 \pi / 3)
\end{gathered}
$$

where $\omega$ is the angular speed at the rated supply frequency.

The fictitious rated currents are given by

$$
\begin{gathered}
i_{A_{-} \text {rated }}=\sqrt{2} I_{\text {rated }} \sin (\omega t-\varphi-\pi / 6) \\
i_{B_{-} \text {rated }}=\sqrt{2} I_{\text {rated }} \sin (\omega t-\varphi-\pi / 6-2 \pi / 3) \\
i_{C_{-} \text {rated }}=\sqrt{2} I_{\text {rated }} \sin (\omega t-\varphi-\pi / 6+2 \pi / 3)
\end{gathered}
$$

where $\varphi$ is given by

$$
\varphi=\cos ^{-1}\left(P F_{\text {rated }}\right)
$$


Then, the modified stator resistance estimation is performed offline applying (21) and (22) using these current and voltage data in (23) and (24).

Of course, the calculation proposed by using these fictitious rated voltages and currents is an approximation and includes some errors. This is because of the considerations of balance and symmetry and the intrinsic error of the nameplate data, which cannot correspond to the actual rated operation point of the IM, because of the aging and losses. Thus, this approach must be adopted only in the case that the motor does not operate close to the rated operation point as an alternative for the modified stator resistance estimation.

\subsection{Induction Motor Efficiency Evaluation}

Considering a typical condition monitoring system for IMs, and the efficiency estimation as one of its features, the main steps of the proposed methodology are described in the following.

\subsubsection{Rotor Speed Estimation}

The induction motor rotor speed is estimated from current data samples packets applying a motor current signature analysis approach. The method is based on the detection of the low-frequency eccentricity components which modulates the fundamental frequency of the IM [1,2]. The rotor speed estimation is preferred over its measurement due to its low-intrusiveness (appropriate for in-service IM efficiency estimation) $[8,17,23]$.

\subsubsection{Rated Speed Correction}

It is necessary that the motor operate close to the IM-rated operation point to perform the modified stator resistance estimation. However, as already mentioned, the nameplate rated speed can include a considerable error. Thus, the indicated rated speed may be, in practice, associated to another torque value and not the indicated rated torque. Thus, a rated speed correction is performed offline before the stator resistance estimation, as proposed by [7], performed by (13).

\subsubsection{Estimation of the Modified Stator Resistance}

In the case of using Method 1, the modified stator resistance estimation is performed by an algorithm based on the process described in the Section 3.1. The algorithm considers the IM rated operation point adopting the corrected rated speed-OP $\left(n^{*}\right.$ rated,$\left.T_{\text {rated }}\right)$-and is only performed when the IM operates close to this point. As the mechanical torque is the unknown parameter (the variable desired to be estimated), the IM rotor rotation speed is the monitored parameter used to measure the proximity of the IM operation point to the rated one. Thus, the algorithm verifies the IM rotor rotation speed periodically, and the computation of (22) is carried out only when this parameter is close enough to the corrected rated speed. If this condition is not fulfilled and the algorithm did not estimate a stator resistance previously, a reference value of stator resistance is used to calculate the AGT. This value can be the "physical" resistance measurement or an estimative value for a motor of that power rating.

In the case of using Method 2, the modified stator resistance estimation is performed offline by the process described in Section 3.2.

\subsubsection{Torque Calculation and Determination of the Efficiency Coefficient}

After the estimation of the modified stator resistance, this value is applied to calculate the torque for any load condition of the induction motor. The AGT torque calculated using this resistance is a good approximation for the shaft torque, as mentioned before. Henceforward, the calculated AGT torque using $R_{S}^{*}$ will be denominated as shaft torque, $T_{\text {shaft }}$. The computation is performed online for each data sample by using (7).

The IM efficiency evaluation is performed by using (9) and considering the estimated shaft torque. 


\section{Methodology for Computing Induction Motor Torque and Efficiency Considering the Selected Methods}

This paper focuses on the proposed IM efficiency estimation method based on AGT using a modified stator resistance estimated with a direct method. This method is analyzed through simulation and experimental tests and compared with other methods for in-service IM efficiency estimation. The methods approached in this paper are (a) the proposed method (AGT with modified stator resistance), (b) the slip method, (c) the modified slip method (with rated speed correction); (d) the ("conventional") AGT method, and (e) the no-load current method. Thus, this section presents the methodology for computing IM efficiency considering the different approached methods.

Both simulation and experimental results have been obtained by using similar computational simulations. The main difference between the two cases is that, in the former, the input signals for the methods come from an IM model (with the parameters of the tested IM), and in the latter, the input signals are measurements (signal acquisition samples) from the real IM used in the tests.

\subsection{Tested Induction Motor}

The simulation tests have been performed with a 0.5-HP 2-pole IM. The rated values and parameters for the IM are presented in Table 1 [24]. The IM was simulated as a dynamic model based on the state-space equations, with inserted mechanical losses [1].

Table 1. Rated data of the induction motor (IM) used in the simulation tests.

\begin{tabular}{cccc}
\hline $\boldsymbol{V}_{\text {rated }}$ & $220(\mathrm{~V})$ & $\boldsymbol{R}_{\boldsymbol{s}}$ & $2.1(\Omega)$ \\
$\boldsymbol{I}_{\text {rated }}$ & $1.18(\mathrm{~A})$ & $\boldsymbol{R}_{\boldsymbol{r}}$ & $0.8663(\Omega)$ \\
$\boldsymbol{f}_{\text {rated }}$ & $60(\mathrm{~Hz})$ & $\boldsymbol{L}_{m}$ & $1.00130(\mathrm{H})$ \\
$\boldsymbol{n}_{\text {rated }}$ & $3500(\mathrm{rpm})$ & $\boldsymbol{L}_{\boldsymbol{s}}$ & $1.02938(\mathrm{H})$ \\
$\boldsymbol{P F}_{\text {rated }}$ & 0.954 & $\boldsymbol{L}_{\boldsymbol{r}}$ & $0.9834(\mathrm{H})$ \\
\hline
\end{tabular}

The experimental tests have also been performed with a 0.5-HP 2-pole IM. The rated values and parameters for the IM are presented in Table 2, where $R_{s}$ is the measured stator resistance.

Table 2. Rated data of the IM used in the experimental tests.

\begin{tabular}{cccc}
\hline $\boldsymbol{V}_{\text {rated }}$ & $220(\mathrm{~V})$ & $\boldsymbol{n}_{\text {rated }}$ & $3450(\mathrm{rpm})$ \\
$\boldsymbol{I}_{\text {rated }}$ & $2.1(\mathrm{~A})$ & $\boldsymbol{P F}_{\text {rated }}$ & 0.697 \\
$f_{\text {rated }}$ & $60(\mathrm{~Hz})$ & $\boldsymbol{R}_{\boldsymbol{s}}$ & $3.144(\Omega)$ \\
\hline
\end{tabular}

Figure 3 presents the schematic diagram of the laboratory setup used for the experimental tests.

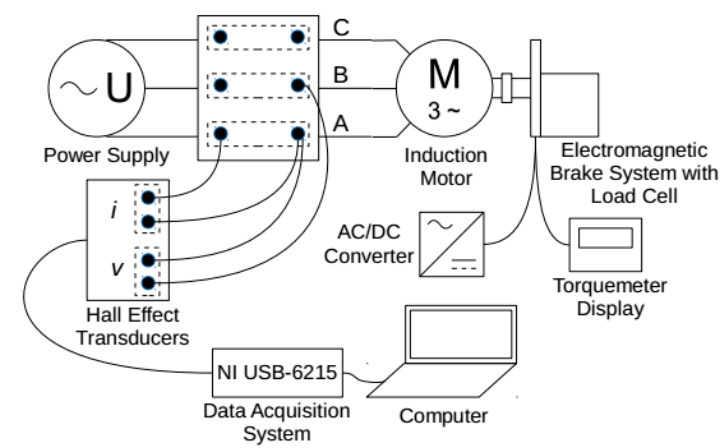

Figure 3. Schematic diagram of the laboratory setup for experimental tests. The Hall Effect transducers are represented only for one phase for purpose of simplifying the diagram, but in practice, there are three sets of transducers. 
Figure 4 presents a photo of the laboratory setup used for the experimental tests, whose items are (1) the voltage and current Hall effect transducers boxes, (2) the box for electrical connections, (3) the induction motor, (4) the electromagnetic brake system with a load cell, (5) the display for torque indication, (6) the AC/DC converter to supply the brake system, and (7) the data acquisition system.

The load/torque variations in the IM are emulated by using an electromagnetic brake system. It was custom-made and compatible with a $0.5-\mathrm{HP}$ two-pole IM. DC voltage (supplied by the AC/DC converter) was used to control the brake, and the shaft torque was measured with a load cell. The display for the torque indication was a digital indicator Contemp ID02-B.

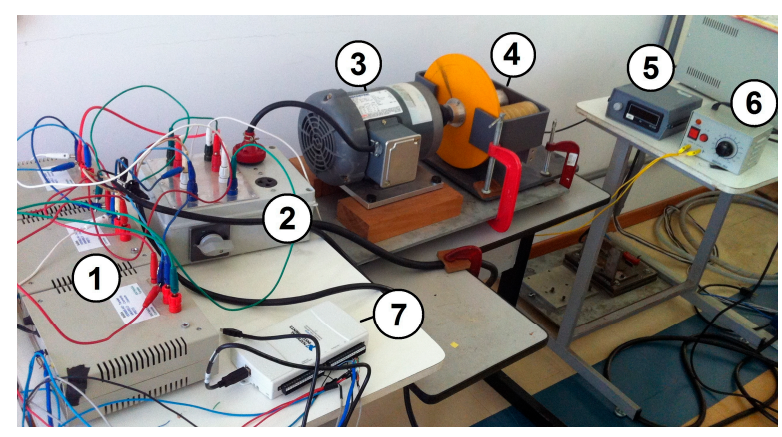

Figure 4. Photo of the laboratory setup for experimental tests.

The Hall effect transducers were three current transducers LEM LA 55-P to measure the IM line currents and three voltage transducers LEM LV 25-P to measure the IM phase-to-phase voltages. The current transducers data are primary nominal current (RMS) $=50(\mathrm{~A})$; primary current, measurement range $=0 \pm 70(\mathrm{~A})$; secondary nominal current $=50(\mathrm{~mA})$; conversion ratio $=1: 1000$; supply voltage $( \pm 5 \%)=0 \pm 12.15(\mathrm{~V})$; and accuracy (at primary nominal current and $\left.25^{\circ} \mathrm{C}\right)= \pm 0.90 \%$ at $\pm 12.15(\mathrm{~V})( \pm 5 \%)$ supply voltage. The voltage transducers data are primary nominal current (RMS) $=10(\mathrm{~mA})$; primary current, measurement range $= \pm 15(\mathrm{~mA})$; secondary nominal current $=25(\mathrm{~mA})$; conversion ratio $=2500: 1000$; supply voltage $( \pm 5 \%)=0 \pm 12.15(\mathrm{~V})$; and accuracy (at primary nominal current and $\left.25^{\circ} \mathrm{C}\right)= \pm 0.90 \%$ at $\pm 12.15(\mathrm{~V})( \pm 5 \%)$ supply voltage.

The transducers secondary sides have been connected to the data acquisition hardware at the Single Ended configuration. The data acquisition system used was the NI USB-6215 module, which has 16-bit, $250(\mathrm{kS} / \mathrm{s})$ single-channel sampling rate. It is provided with 16 analog inputs, two analog outputs, four digital input lines, four digital output lines, four programmable input ranges ( \pm 0.2 to $\pm 10 \mathrm{~V}$ ) per channel, digital triggering, and two counter/times. The analog inputs data are maximum voltage $=10(\mathrm{~V})$; maximum voltage range $=-10(\mathrm{~V}), 10(\mathrm{~V})$; accuracy at maximum voltage range $=2.69(\mathrm{mV})$; minimum voltage range $=-200(\mathrm{mV}), 200(\mathrm{mV})$; and accuracy at minimum voltage range $=0.088(\mathrm{mV})$. The signals were acquired with $8000(\mathrm{~Hz})$ sampling frequency, which corresponds to a $1.25 \times 10^{-4}$ (s) sampling time. Each data acquisition consisted in the three-line currents and three phase-to-phase voltages of the machine at a given load condition. Each data acquisition length was 30 (s), but only 5 (s) of each one was used for the analysis presented in this paper. The signals were transmitted from the data acquisition module to a personal computer via USB cable. A script was used to acquire and process the data from the module and make them compatible with the computational simulations, which will be described in the next items.

\subsection{Induction Motor Initialization Parameters}

In both cases, the first step is to load a file with the IM parameters. The parameters include $T_{S}$ (sampling rate), $f_{1}$ (supply frequency), $P_{\text {rated }}$ (rated power), $N P$ (number of poles), $R_{s}$ (measured stator resistance), $n_{\text {rated }}$ (rated speed), $\eta_{\text {rated }}$ (rated efficiency), $V_{\text {rated }}$ (rated voltage), $I_{\text {rated }}$ (rated current), $I_{0}$ (no load current), $P F_{\text {rated }}$ (power factor), and $n^{*}$ rated (corrected rated speed). 
In the case of the IM model (related to the simulation results), there are other parameters needed to be loaded in the beginning of the procedure: $R_{r}$ (rotor resistance), $L_{r}$ (rotor inductance), $L_{S}$ (stator inductance), $L_{m}$ (mutual inductance), $J$ (moment of inertia), and $K_{0}$ (factor for calculating and inserting losses in the model). These parameters are used for the dynamic simulation of the induction motor, considering the state-space equations.

\subsection{Induction Motor Input and Output Signals}

In the case of the simulation with the IM model (used for the simulation tests), the motor inputs are the three phase voltages and reference torque (load torque). These signals go to the IM dynamic model, consisting of the IM state-space equations, and this model provides as outputs the three-phase currents and the rotor rotation speed. Thus, these parameters (three-phase voltages and currents and rotor rotation speed) are taken as inputs for the method to compute the induction motor torque and efficiency. The load torque is used only for the purpose of comparison (it is the reference torque). Figure 5 illustrates the induction motor model.

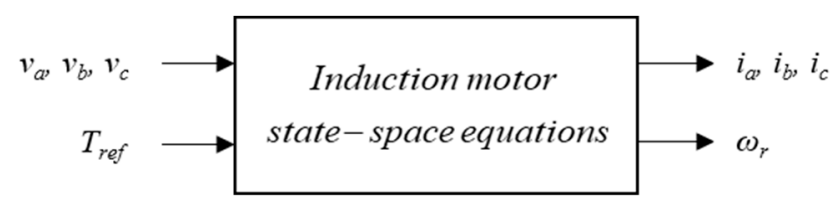

Figure 5. Induction motor dynamic model of the simulation tests.

In the case of experimental tests, a real IM was used. In this case, the inputs are also the three-phase voltages to supply the motor and the load torque (imposed by using the electromagnetic brake). The outputs of the motor are the three phase currents and the rotor rotation speed. The voltage and current signals are measured by using Hall effect transducers, and the signals are acquired by using proper hardware as presented in Figure 3. The torque is measured by using a torque meter, and the rotor speed is measured with a laser tachometer (in the case of an in-service IM efficiency estimation, the rotor speed can be estimated from current signature analysis [1]). Thus, these parameters (three phase voltages and currents and rotor rotation speed) are inputs for the method to compute the induction motor torque and efficiency. The load torque is used only for the purpose of comparison (it is the reference torque). Figure 6 illustrates the parameters of the IM used in the experimental tests.

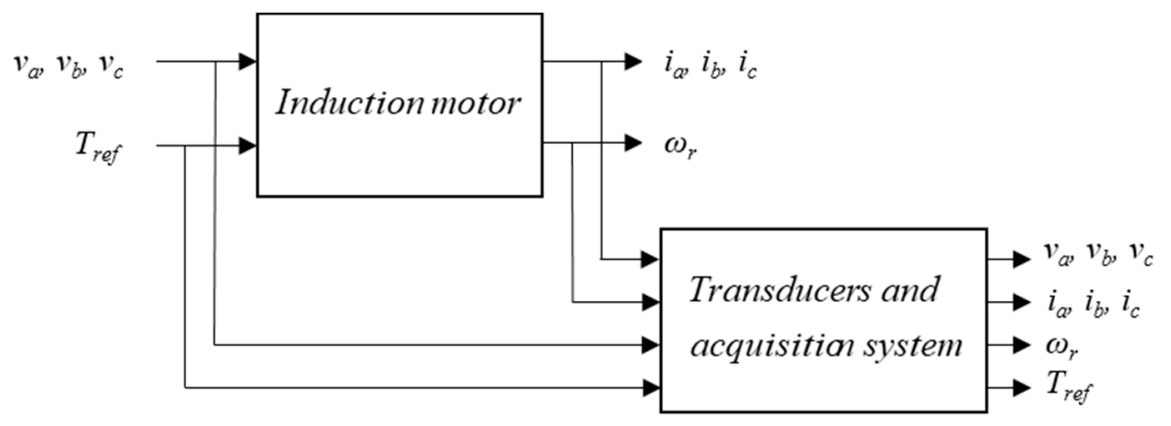

Figure 6. Parameters of the IM used in the experimental tests.

Once the required data are available (three-phase voltages and currents and rotor rotation speed), they are used to compute the induction motor torque and efficiency, depending on the method, as explained in the following. An observation is that the phase-to-phase voltages were later obtained from the phase-to-neutral voltages. 


\subsection{Induction Motor Shaft Torque Estimation by the Selected Methods}

The next items present the computation of the induction motor torque and efficiency for each selected method.

\subsubsection{Slip Method and Modified Slip Method}

The slip method procedure is illustrated in the Figure 7, where there is indication of the required inputs, the equations, and the output torque. The procedure is executed for each data sample, providing the dynamic shaft torque.

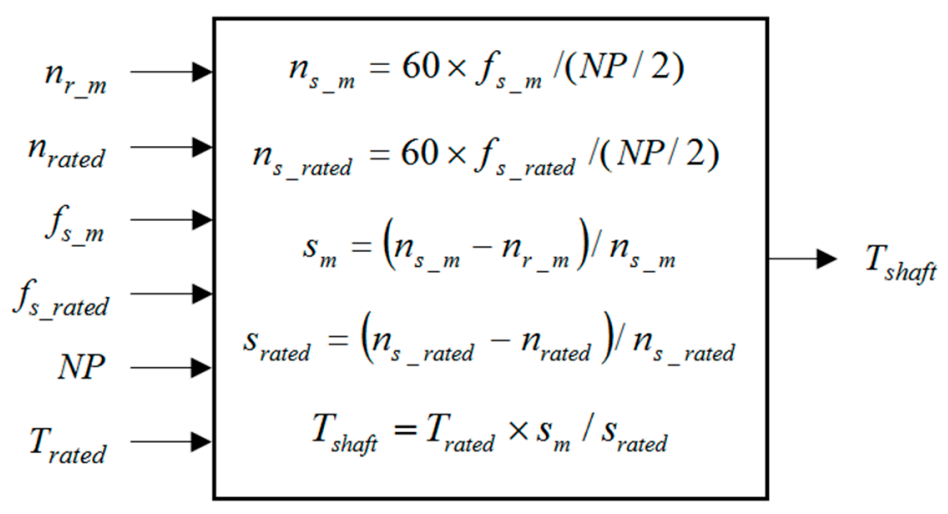

Figure 7. Slip method procedure.

In Figure $7, n_{r_{-} m}$ is the "measured" rotor rotation speed; $n_{\text {rated }}$ is the rated speed; $f_{s_{-} m}$ is the "measured" synchronous frequency; $f_{s_{-} r a t e d}$ is the rated synchronous frequency; NP is the number of poles; $T_{\text {rated }}$ is the rated torque; $n_{s_{-} m}$ is the measured synchronous speed; $n_{s_{-} \text {rated }}$ is the rated synchronous speed; $s_{m}$ is the measured slip; $s_{\text {rated }}$ is the rated slip; $T_{\text {shaft }}$ is the shaft torque.

In the case of the modified slip method, the same procedure is used. The only difference is that instead of using the rated speed, it is used the corrected rated speed, calculated with (13).

\subsubsection{AGT Method and Proposed AGT-Based Method}

The AGT method is illustrated in the Figure 8, where there is indication of the required inputs, the equations, and the output torque. The procedure is executed for each data sample, providing the dynamic shaft torque.

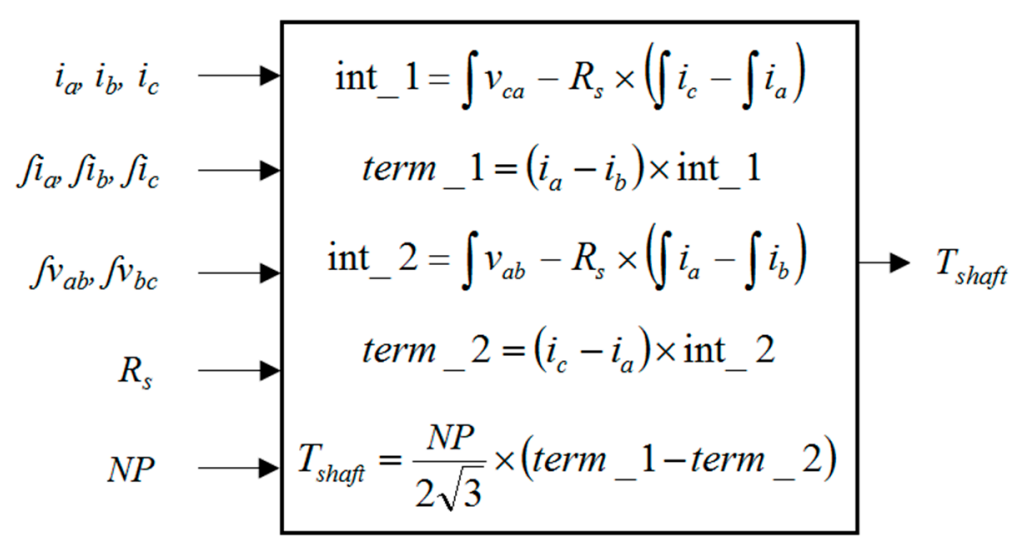

Figure 8. Air-Gap Torque (AGT) method procedure. 
In Figure $8, i_{a}, i_{b}, i_{c}$ are the phase currents; $\int i_{a}, \int i_{b}, \int i_{c}$ are the integral of the phase currents; $\int v_{a b}$, $\int v_{b c}$ are the integral of the phase-to-phase voltages; and $R_{s}$ is the stator resistance. The integrals are computed by numerical integral blocks using the trapezoidal method.

In the case of the conventional AGT method, the measured stator resistance is used. In the case of the proposed AGT based method, the only difference is that instead of the measured stator resistance, it is used the estimated modified stator resistance.

The modified stator resistance is computed by using a direct method, as presented in Section 3.

\subsubsection{No-Load Current Method}

The no-load current method is illustrated in the Figure 9, where there is indication of the required inputs, the equations, and the output torque. The procedure is executed for each data sample, providing the dynamic shaft torque.

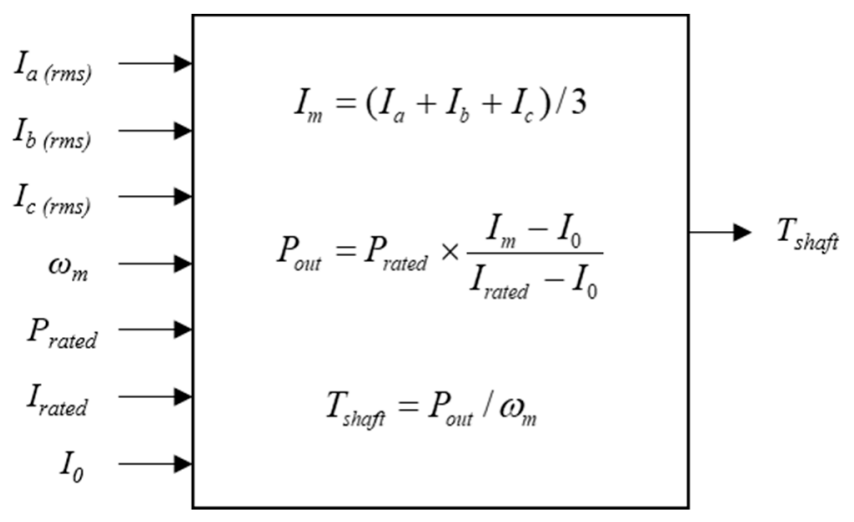

Figure 9. No load current method procedure.

In Figure $9, I_{a(r m s)}, I_{b(r m s)}, I_{c}(r m s)$ are the phase currents RMS values (obtained by using specific blocks for this purpose), $\omega_{m}$ is the "measured" rotor speed, $P_{\text {rated }}$ is the rated power, $I_{\text {rated }}$ is the rated current, and $I_{0}$ is the no-load current.

\subsection{Efficiency Evaluation}

As long as the shaft torque is computed, using one of the methods presented before, the efficiency is computed by using the procedure illustrated in the Figure 10. The acquired signals of $i_{a}, v_{c a}, i_{b}$, and $v_{b c}$ are mathematically manipulated, and the arithmetic means are obtained and summed in order to compute the electrical power. The multiplication of $T_{\text {shaft }}$ and $\omega_{r}$ result in the shaft power. Finally, the efficiency, $\eta$, is obtained by the division of the shaft power by the electrical power (input power).

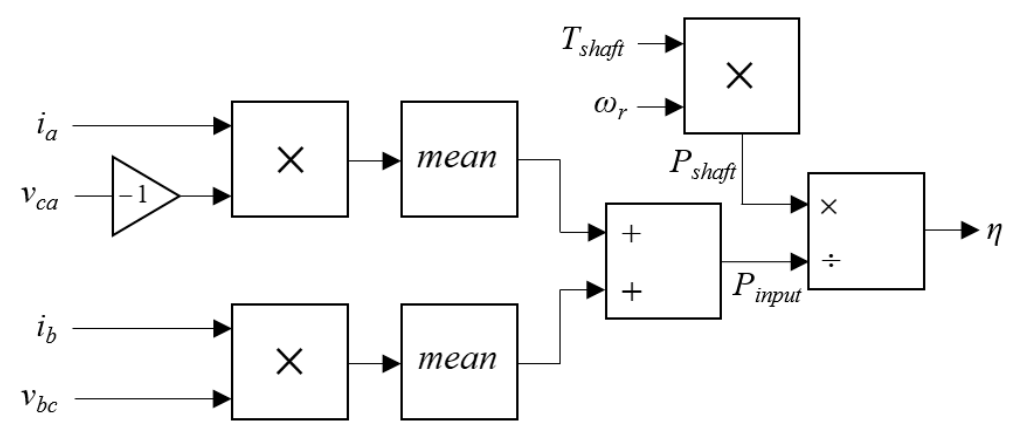

Figure 10. Efficiency computation. 
In the case of the efficiency computation results that will be presented in the next sections, different load torque conditions have been imposed to the induction motor, to produce the results that will be explained.

\section{Induction Motor Shaft Torque and Modified Stator Resistance Results}

\subsection{Simulation Results}

This section presents the simulation results for the proposed methodology. The first step was the rated speed correction procedure, which resulted in a value of $n^{*}$ rated $=3564.06(\mathrm{rpm})$ for the IM modeled with mechanical losses. Then, the simulation was implemented.

\subsubsection{Case 1: Conventional Estimation of the Modified Stator Resistance ("Method 1")}

In the case of simulation tests, the modified stator resistance estimation was performed when the motor worked at the rated load condition, i.e., when the IM operated with the corrected rated speed. Figure 11a presents the IM dynamic torque estimation during the computational simulation. Figure $11 \mathrm{~b}$ presents the corresponding stator resistance estimation by using the conventional method ("Method 1").

From time $t=0$ (s) to $t=1.5(\mathrm{~s})$, the estimator is off, and the torque is estimated considering the theoretical resistance value, $R_{S}=2.1(\Omega)$. During this period, there is a difference between the two torque curves in Figure 11a. At $t=1.5(\mathrm{~s})$, the estimator starts. Within some data samples, the resistance reaches $9.453(\Omega)$, which can be noticed in Figure 11b. From this instant, the torque is calculated considering this estimated resistance. After this instant, the difference between the two torque curves decreases and the torque curves coincide, as can be observed in Figure 11a.

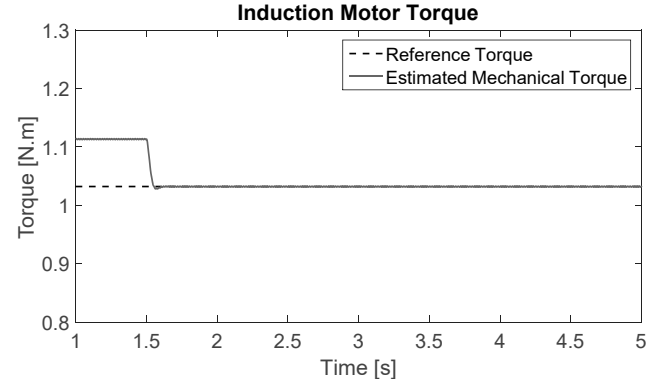

(a)

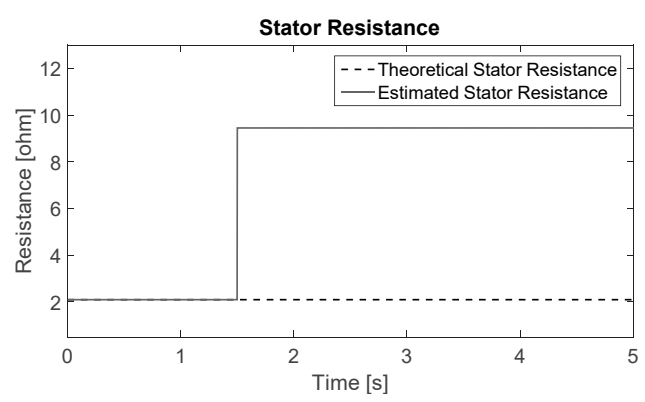

(b)

Figure 11. Conventional method to estimate the modified stator resistance ("Method 1")—simulation results for (a) IM torque estimation and (b) IM modified stator resistance estimation.

Thus, the estimated value for the modified stator resistance was $R_{s}^{*}=9.453(\Omega)$. This value is larger than the theoretical value, which evidences the additional term related to the IM losses. The modified stator resistance is estimated close to the rated operation point, but this value is then used to estimate the mechanical torque for the other operating conditions of the IM.

5.1.2. Case 2: Alternative Estimation of the Modified Stator Resistance from the Nameplate Data ("Method 2")

In the case, the IM does not operate close to the rated operation point, and the modified stator resistance is obtained by using the alternative method proposed in Section 3.2 ("Method 2"). The fictitious values for voltages and currents are obtained and used in the computational simulation. Then, the modified stator resistance is estimated by using (21) and (22).

Figure $12 \mathrm{a}, \mathrm{b}$ presents the estimation of the IM torque and the corresponding stator resistance considering the fictitious values of rated voltages and currents. The estimation of the stator resistance 
starts at $t=1.5(\mathrm{~s})$, and, after this instant, it can be noticed in Figure 12a that the estimated torque becomes practically equal the reference torque. The estimated value for the modified stator resistance was $R_{s}^{*}=9.479(\Omega)$, which was very close to the value obtained by using the conventional method.

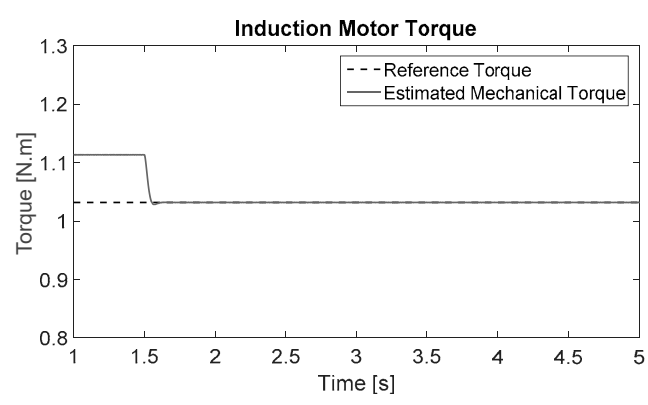

(a)

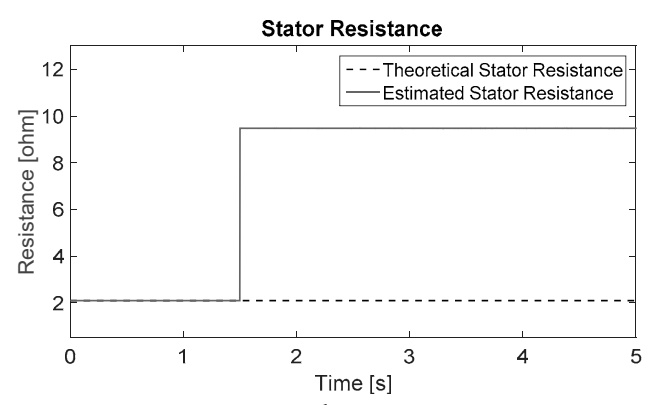

(b)

Figure 12. Alternative method to estimate the modified stator resistance ("Method 2")—simulation results for (a) IM torque estimation and (b) IM modified stator resistance estimation.

\subsection{Experimental Results}

This section presents preliminary experimental results for the proposed methodology.

It is important to say that there are some peculiarities when performing the efficiency estimation using the acquired voltage and currents. First, the supply voltage was distorted with harmonics, which could produce large oscillations on the estimated torque. In order to fix this issue, an IIR (Infinite Impulse Response) low pass filter was included in the simulation to the acquired voltages and currents. Second, as in the AGT method, the fluxes are calculated from an integration of voltages and currents, a DC offset could cause the fluxes to grow as a ramp. Thus, high-pass filtering has been used on the voltages and currents just before the integration, eliminating any possible DC offset.

The first step was the procedure of rated speed correction, in which the speed $n^{*}$ rated $=3505.33$ (rpm) was obtained for the induction motor. Then, the simulation was executed.

\subsubsection{Case 1: Conventional Estimation of the Modified Stator Resistance ("Method 1")}

The modified stator resistance estimation was performed for the tested load condition closest to the rated one. Figure 13a presents the IM dynamic torque estimation during the computational simulation. Figure 13b presents the corresponding stator resistance estimation by using the conventional method ("Method 1").

From time $t=0$ (s) to $t=1(\mathrm{~s})$, the estimator is off, and the torque is estimated considering the theoretical resistance value, $R_{S}=3.144(\Omega)$, which was the measured resistance for the motor at standstill. During this period, it can be noticed a difference between the two torque curves in Figure 13a. At $t=1(\mathrm{~s})$, the estimator starts. Within some data samples, the resistance converges to $12.91(\Omega)$, which can be noticed in Figure 13b. From this instant, the torque is calculated considering this estimated resistance. After this instant, the difference between the two torque curves decreases and is kept very small, as can be observed in Figure 13a. 


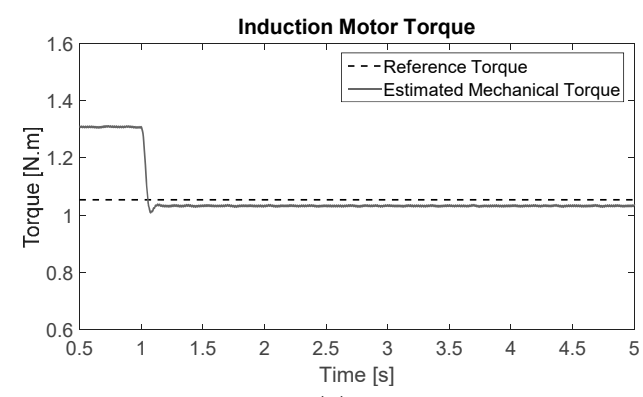

(a)

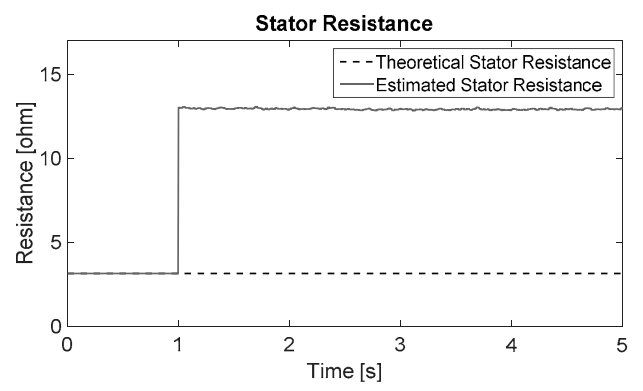

(b)

Figure 13. Conventional method to estimate the modified stator resistance ("Method 1")—experimental results for (a) IM torque estimation and (b) IM modified stator resistance estimation.

Thus, the estimated value for the modified stator resistance was $R_{S}^{*}=12.91(\Omega)$. This value is larger than the theoretical value, which evidences the additional term related to the IM losses. As mentioned before, the modified stator resistance is estimated close to the rated operation point, but this value is then used to estimate the mechanical torque for the other operating conditions of the IM.

5.2.2. Case 2: Alternative Estimation of the Modified Stator Resistance from the Nameplate Data ("Method 2")

In case the IM does not operate close to the rated operation point, the modified stator resistance is obtained by using the alternative method proposed in Section 3.2 ("Method 2"). The fictitious values for voltages and currents are obtained from nameplate data and used in the simulation. Then, the modified stator resistance is estimated by using (21) and (22).

Figure $14 \mathrm{a}, \mathrm{b}$ presents the estimation of the IM torque and the corresponding stator resistance considering the fictitious values of rated voltages and currents. The estimation of the stator resistance starts at $t=1$ (s), and, after this instant, it can be noticed in Figure 14a that the estimated torque becomes practically equal the reference torque. The estimated value for the modified stator resistance was $R_{s}^{*}=12.74(\Omega)$, which was close to the value obtained by using the conventional method ("Method 1 ").

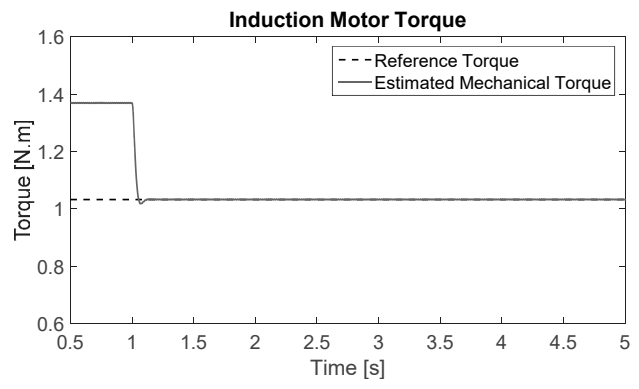

(a)

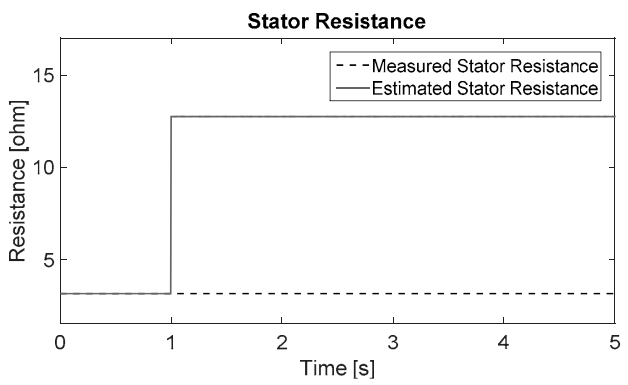

(b)

Figure 14. Alternative method to estimate the modified stator resistance ("Method 2")—experimental results for (a) IM torque estimation and (b) IM modified stator resistance estimation.

\section{Induction Motor Efficiency Results}

This section presents the induction motor efficiency for simulation and experimental tests, considering the proposed methodology and the other selected methods.

\subsection{Proposed Methodology}

After the stator resistance estimation, considering the Method 1 and Method 2, different load conditions were imposed to the IM, and the respective efficiency coefficients were calculated. Figure 15 
presents the efficiency plot, where the $x$-axis are the load conditions related to the rated condition. The measured efficiency was obtained by using (9). In the case of simulation tests, $T_{\text {shaft }}$ is the reference mechanical torque and $\omega_{r}$ is the rotation speed provided by the IM model. In the case of experimental tests, $T_{\text {shaft }}$ is the measured torque and $\omega_{r}$ is the measured rotor speed. The proposed methodology efficiency was obtained by using (9) and considering $T_{\text {shaft }}$ as the torque estimated by using AGT with the estimated modified stator resistance (AGT with Estimated $R_{s}$-Method 1 and Method 2). In the case of simulation tests, $\omega_{r}$ is the rotation speed provided by the IM model, and in the case of experimental tests, it is the measured rotor speed.

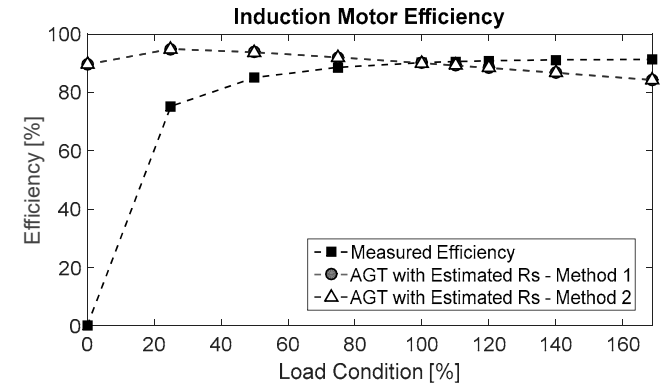

(a)

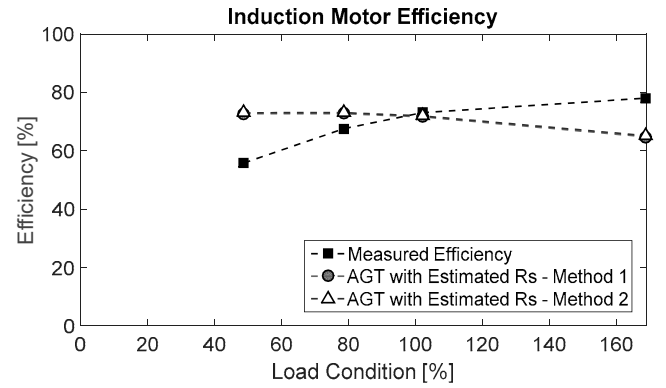

(b)

Figure 15. IM efficiency estimation using the proposed methodology-(a) simulation and (b) experimental results.

The efficiency values computed by using AGT with estimated stator resistance with Method 1 and Method 2 were practically the same. In the case of simulation results, the efficiency estimation error (considering the proposed methodology in comparison with the theoretical values) was small from load condition of $50 \%$ and so on. It can be noticed that, as the load condition is closer to the rated condition, the error decreases. Also, for load conditions between $75 \%$ and $150 \%$, the error is smaller than $5 \%$. In the case of experimental tests, the efficiency estimation error was small for the load conditions near $80 \%$ and $100 \%$, being about $8 \%$ and $2 \%$ for these conditions, respectively. Also, the error for the biggest load condition (near 168\%) was about $16 \%$. Thus, the results for the proposed methodology are promising.

\subsection{Comparison among Induction Motor Efficiency Evaluation Methods}

The IM efficiency calculated by using the proposed methodology was compared with the efficiency coefficients calculated by using other methods indicated for in-service IMs. As already mentioned, the methods considered for comparison were the standard slip method [8], the modified slip method with rated speed correction [7], the standard air-gap torque method [8], and the no-load current method [13]. Figure 16 presents the efficiency estimation percentage errors for all the considered methods for the simulation and experimental results. The errors were calculated as the difference between the efficiency coefficient obtained with the method under analysis and the theoretical efficiency. They are presented in percentage with relation to the theoretical efficiency. It is important to say that the theoretical efficiency (expected efficiency) is that calculated with the real torque and speed values at each load condition. 


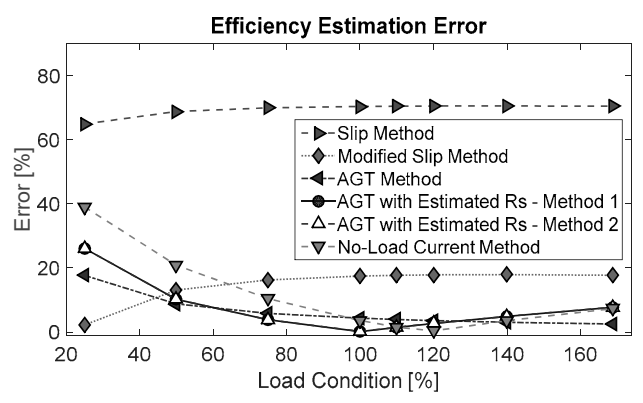

(a)

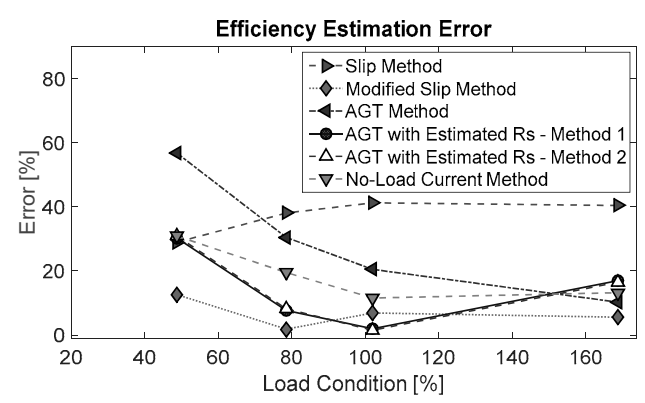

(b)

Figure 16. IM efficiency estimation error-(a) simulation and (b) experimental results.

In the case of simulation results (Figure 16a), the proposed methodology (AGT with Estimated $R_{s}$-Method 1 and Method 2) and AGT method presented the smallest errors. The errors obtained by these methods were less than $8 \%$ for load conditions above $75 \%$. In addition, the proposed methodology conducted to the smallest error for load conditions between $75 \%$ and $110 \%$. The errors obtained by using the proposed methodology were small for the different load conditions from $50 \%$ and so on. The no-load current method presented small errors from load conditions above $75 \%$. The modified slip method and mainly the slip method presented the biggest errors. In the case of experimental results (Figure 16b), the proposed methodology (AGT with Estimated $R_{s}-$ Method 1 and Method 2) and modified slip method presented the smallest errors. The errors obtained by these two methods were less than $10 \%$ for load conditions between $80 \%$ and $140 \%$. In addition, the proposed methodology presented the smallest error for load conditions near $100 \%$. The errors obtained by using the proposed methodology were small for the load conditions near $80 \%$ and $100 \%$. The results show the effectiveness of the proposed methodology for in-service IMs efficiency estimation.

A final remark is made for the slip method. As already explained, this method is quite sensitive to the rated speed, because the method is a linearization of the IM speed versus torque curve. By comparing the rated speed and corrected speed values for simulation and experimental tests, it can be noticed that the difference of the rated speed and corrected rated speed values is larger for the simulation tests (about $64 \mathrm{rpm}$ ) than for the experimental tests (about $55 \mathrm{rpm}$ ). This may have caused the larger error for the slip method in the case of the simulation results than the experimental results. Another aspect may be related to the IM parameters, taken from [24], which mean a representation for the IM modeling. They may be less representative (which impacts on the speed computation by the IM model) than the effectively measured values of the IM in the case of experimental results.

\section{Conclusions}

This paper approached the estimation of a modified stator resistance including the mechanical losses effect to be used in the AGT method for IM efficiency estimation. The paper proposed some improvements in the estimation of this modified stator resistance by using a direct method. Moreover, it proposed an alternative method to estimate this resistance directly from the nameplate data and using voltage and current fictitious signals. This last approach is an alternative to estimate the modified stator resistance when the induction motor does not operate close enough to the rated operation point. The main advantages of the proposed methodology are its ease of implementation and that it only relies on line currents, line voltages, and nameplate data, being appropriate to estimate the efficiency for in-service induction motors.

The proposed methodology was studied and validated through simulation and preliminary experimental tests performed for a $0.5-\mathrm{HP}$ three-phase induction motor. Moreover, a comparison among low-intrusive efficiency estimation methods, including the proposed one, has been presented for the tested motors. In the case of the simulation results, the estimated stator resistance used in the AGT method produced a small error in the torque curve of the induction motor and also in 
the efficiency estimation, considering the different load conditions. In the case of the experimental results, the proposed methodology conduced to small error of efficiency estimation mainly for the load conditions close to $80 \%$ and $100 \%$. Regarding the alternative method to estimate the modified stator resistance directly from the nameplate data (Method 2), it is important to say that the presented experimental results are preliminary, and the method should be tested on the field in the future in order to have its effectiveness really proved. Finally, it is expectedto get better results for efficiency evaluation of larger motors, which can be studied in future works.

Acknowledgments: The authors would like to thank the National Council for Scientific and Technological Development (CNPq), Coordination for the Improvement of Higher Education Personnel (CAPES), and the Brazilian Electricity Regulatory Agency Research and Development (ANEEL R\&D) for supporting this project.

Author Contributions: Camila Paes Salomon, Wilson Cesar Sant'Ana, and Germano Lambert-Torres conceived and designed the experiments; Camila Paes Salomon, Luiz Eduardo Borges da Silva, Erik Leandro Bonaldi, and Levy Ely de Lacerda de Oliviera performed the experiments; Camila Paes Salomon, Wilson Cesar Sant'Ana, and Germano Lambert-Torres analyzed the data; Luiz Eduardo Borges da Silva, Erik Leandro Bonaldi, and Levy Ely de Lacerda de Oliviera contributed analysis tools; and Camila Paes Salomon, Wilson Cesar Sant'Ana, and Germano Lambert-Torres wrote the paper.

Conflicts of Interest: The authors declare no conflict of interest.

\section{Nomenclature}

\section{Parameters}

$P_{\text {rated }}$

$I_{0}$

$I_{\text {rated }}$

$R_{S}$

NP

$n_{S}$

$n_{\text {rated }}$

$s_{\text {rated }}$

$n_{\text {syn } 60}$

$V_{\text {rated }}$

$\omega$

$P F_{\text {rated }}$

$\varphi$

$R_{r}$

$L_{m}$

$L_{S}$

$L_{r}$

$T_{S}$

$f_{1}$

$\eta_{\text {rated }}$

J

$K_{0}$

$f_{\text {s_rated }}$

$n_{\text {s_rated }}$

Variables

$P_{\text {shaft }}$

$I_{m}$

$v_{p}$

$\psi_{p}$

$i_{p}$

Time parameter

Rated shaft power

No load (RMS) current

Rated (RMS) current

Stator resistance

Number of poles

Synchronous speed

Rated speed

Rated slip

Synchronous speed at rated frequency

Rated phase-to-phase (RMS) voltage

Angular speed at rated supply frequency

Rated power factor

Phase angle between voltage and current

Rotor resistance

Magnetizing inductance

Stator inductance

Rotor inductance

Sampling rate

Supply frequency

Rated efficiency

Moment of inertia

Factor for calculating and inserting losses in the induction motor model

Rated synchronous frequency

Rated synchronous speed

Current operation shaft power

Measured RMS current

Phase-to-neutral voltage ( $p=a, b$ or $c)$

Flux linkage of winding $p(p=a, b$ or $c)$

Phase current $(p=a, b$ or $c)$

Instantaneous input power 


\begin{tabular}{|c|c|}
\hline$T_{e}$ & Air-gap torque \\
\hline$v_{p p}$ & Phase-to-phase voltage $(p p=a b, b c$ or $c a)$ \\
\hline$T_{\text {shaft }}$ & Shat torque \\
\hline$\omega_{r}$ & Rotor rotation speed \\
\hline$P_{\text {input }}$ & Electrical real power (input power) \\
\hline$W_{f w}$ & Friction and windage loss \\
\hline$W_{l l}$ & Rotor stray load loss \\
\hline$T_{m}$ & Current operation torque \\
\hline$n_{m}$ & Current operation speed \\
\hline$s_{m}$ & Current operation slip \\
\hline$n_{\text {rated }}^{*}$ & Corrected rated speed \\
\hline$n_{\text {syn } 1}$ & Synchronous speed at an operation point "\#1" \\
\hline$n_{\text {syn } 2}$ & Synchronous speed at an operation point "\#2" \\
\hline$S^{*}$ rated & Corrected rated slip \\
\hline$R_{S}^{*}$ & Modified stator resistance \\
\hline$K_{A}$ & Auxiliary term for the modified stator resistance calculation \\
\hline$K_{B}$ & Auxiliary term for the modified stator resistance calculation \\
\hline$v_{p p \_r a t e d}$ & Rated phase-to-phase voltage $(p p=a b, b c$ or $c a)$ \\
\hline$T_{\text {ref }}$ & Reference torque \\
\hline$n_{r \_} m$ & "Measured" rotor rotation speed \\
\hline$f_{S \_m}$ & "Measured" synchronous frequency \\
\hline$n_{S \_} m$ & "Measured" synchronous speed \\
\hline
\end{tabular}

\section{References}

1. Salomon, C.P.; Santana, W.C.; Borges da Silva, L.E.; Lambert-Torres, G.; Bonaldi, E.L.; de Oliveira, L.E.L.; Borges da Silva, J.G. Induction Motor Efficiency Evaluation using a New Concept of Stator Resistance. IEEE Trans. Instrum. Meas. 2015, 64, 2908-2917. [CrossRef]

2. Merizalde, Y.; Hernández-Callejo, L.; Duque-Perez, O. State of the Art and Trends in the Monitoring, Detection and Diagnosis of Failures in Electric Induction Motors. Energies 2017, 10, 1056. [CrossRef]

3. Araujo, B.T.; Bernardes, J.V., Jr.; Bortoni, E.C.; Lambert-Torres, G. Synchronous Machine Parameters Evaluation with a Hybrid Particle Swarm Optimization Algorithm. Electr. Power Compon. Syst. 2018, 45, 1962-1971. [CrossRef]

4. Leite, V.C.M.N.; Borges da Silva, J.G.; Veloso, G.F.C.; Borges da Silva, L.E.; Lambert-Torres, G.; Bonaldi, E.L.; Oliveira, L.E.L. Detection of Localized Bearing Faults in Induction Machines by Spectral Kurtosis and Envelope Analysis of Stator Current. IEEE Trans. Ind. Electr. 2015, 62, 1855-1865. [CrossRef]

5. Institute of Electrical and Electronics Engineers (IEEE). IEEE Standard Test Procedure for Polyphase Induction Motors and Generators; IEEE Standard 112-2004; IEEE: Piscataway, NJ, USA, 2004.

6. Bastiaensen, C.; Deprez, W.; Symens, W.; Driesen, J. Parameter Sensitivity and Measurement Uncertainty Propagation in Torque-Estimation Algorithms for Induction Machines. IEEE Trans. Instrum. Meas. 2008, 57, 2727-2732. [CrossRef]

7. Zhang, H.; Zanchetta, P.; Bradley, K.J.; Gerada, C.A. Low-Intrusion Load and Efficiency Evaluation Method for In-Service Motors Using Vibration Tests with an Accelerometer. IEEE Trans. Ind. Appl. 2010, 46, 1341-1349. [CrossRef]

8. Lu, B.; Habetler, T.G.; Harley, R.G. A survey of efficiency-estimation methods for in-service induction motors. IEEE Trans. Ind. Appl. 2006, 42, 924-933.

9. Pires, V.F.; Kadivonga, M.; Martins, J.F.; Pires, A.J. Motor square current signature analysis for induction motor rotor diagnosis. Measurement 2013, 46, 942-948. [CrossRef]

10. Medina-García, J.; Sánchez-Rodríguez, T.; Galán, J.A.G.; Delgado, A.; Gómez-Bravo, F.; Jiménez, R. A Wireless Sensor System for Real-Time Monitoring and Fault Detection of Motor Arrays. Sensors 2017, 17, 469. [CrossRef] [PubMed]

11. Amezquita-Sanchez, J.P.; Valtierra-Rodriguez, M.; Perez-Ramirez, C.A.; Camarena-Martinez, D.; Garcia-Perez, A.; Romero-Troncoso, R.J. Fractal dimension and fuzzy logic systems for broken rotor bar detection in induction motors at start-up and steady-state regimes. Meas. Sci. Technol. 2017, 28. [CrossRef] 
12. Silva, W.L.; Lima, A.M.N.; Oliveira, A. A Method for Measuring Torque of Squirrel-Cage Induction Motors without Any Mechanical Sensor. IEEE Trans. Instrum. Meas. 2015, 64, 1223-1231. [CrossRef]

13. Hydraulics \& Pneumatics: Rightsize Your Electric Motors. Available online: http://hydraulicspneumatics. com/200/TechZone/HydraulicPumpsM/Article/False/21602/TechZone-HydraulicPumpsM (accessed on 22 May 2017).

14. Siraki, A.; Pillay, P. An In Situ Efficiency Estimation Technique for Induction Machines Working with Unbalanced Supplies. IEEE Trans. Energy Convers. 2012, 27, 85-95. [CrossRef]

15. Grewal, G.S.; Singh, B. Efficiency determination of in-service induction machines using gravitational search optimization. Measurement 2018, 118, 156-163. [CrossRef]

16. Hsu, J.S.; Scoggins, B.P. Field test of motor efficiency and load changes through air-gap torque. IEEE Trans. Energy Convers. 1995, 10, 477-483. [CrossRef]

17. Lu, B.; Habetler, T.G.; Harley, R.G. A Nonintrusive and In-Service Motor-Efficiency Estimation Method Using Air-Gap Torque with Considerations of Condition Monitoring. IEEE Trans. Ind. Appl. 2008, 44, 1666-1674. [CrossRef]

18. Herndler, B.; Barendse, P.; Khan, M.A. Considerations for improving the non-intrusive efficiency estimation of induction machines using the air gap torque method. In Proceedings of the 2011 IEEE Electric Machines \& Drives Conference (IEMDC), Niagara Falls, ON, Canada, 15-18 May 2011; pp. 1516-1521.

19. Lima-Filho, A.C.; Gomes, R.D.; Adissi, M.O.; Borges da Silva, T.A.; Belo, F.A.; Spohn, M.A. Embedded System Integrated into a Wireless Sensor Network for Online Dynamic Torque and Efficiency Monitoring in Induction Motors. IEEE/ASME Trans. Mechatron. 2012, 17, 404-414. [CrossRef]

20. Hsu, J.S. Monitoring of defects in induction motors through air-gap torque observation. IEEE Trans. Ind. Appl. 1995, 31, 1016-1021. [CrossRef]

21. Wang, F.; Zhang, Z.; Mei, X.; Rodríguez, J.; Kennel, R. Advanced Control Strategies of Induction Machine: Field Oriented Control, Direct Torque Control and Model Predictive Control. Energies 2018, 11, 120. [CrossRef]

22. Ojo, J.O.; Ostovic, V.; Lipo, T.A.; White, J.C. Measurement and computation of starting torque pulsations of salient pole synchronous motors. IEEE Trans. Energy Convers. 1990, 5, 176-182. [CrossRef]

23. Salomon, C.P.; Santana, W.C.; Lambert-Torres, G.; Borges da Silva, L.E.; Bonaldi, E.L.; de Oliveira, L.E.L.; Borges da Silva, J.G.; Pellicel, A.; Figueiredo, G.C.; Lopes, M.A.A. Discrimination of Synchronous Machines Rotor Faults in Electrical Signature Analysis Based on Symmetrical Components. IEEE Trans. Ind. Appl. 2017, 53, 3146-3155. [CrossRef]

24. Nakhaeinejad, M.; Bryant, M.D. Observability analysis for model-based fault detection and sensor selection in induction motors. Meas. Sci. Technol. 2011, 22, 1-10. [CrossRef]

(c) 2018 by the authors. Licensee MDPI, Basel, Switzerland. This article is an open access article distributed under the terms and conditions of the Creative Commons Attribution (CC BY) license (http://creativecommons.org/licenses/by/4.0/). 